\title{
Economy Versus Environment: How Corporate Actors Harm Both
}

\author{
Pamela Davies $^{1} \cdot$ Mònica Pons Hernandez ${ }^{2} \cdot$ Tanya Wyatt $^{1}$ \\ Published online: 19 March 2019 \\ (c) The Author(s) 2019
}

\begin{abstract}
The reshaping of the planet by people is having significant consequences for the environment and for human communities. Even though the degradation is visible and pervasive, much of the harm inflicted by humans remains outside the realm of and is not addressed by our criminal justice systems. Such harms tend not to be criminalized and while they may be regulated, such regulation has not led to the overall preservation of the environment or to non-humans. Furthermore, weak and uneven environmental regulations across the globe often have not led to local communities enjoying the economic prosperity from which corporations have benefited greatly. We will demonstrate this complex relationship between the economy and the environment by revisiting the closure of Rio Tinto Alcan's Lynemouth aluminum plant in North East England. Through a literature review and document analysis, we present the past and current socio-economic and environmental contexts of a deprived community entangled in global efforts to protect and improve the environment. Our research reveals a discourse from corporations promoting their social and environmental responsibility in a community that faces socio-economic marginalization and environmental challenges.
\end{abstract}

\section{Introduction}

It has been argued that we are now in a new geological era, the "Anthropocene" (see Crutzen and Stoermer 2000), in which the impact that humans have had on the planet is the defining feature. As Shearing (2015: 257) asserts: "Humans can no longer be conceived of as social actors operating exclusively between a social sphere of human-to-human engagements. We must be conceived of as integral to earth systems. We [...] significantly reshaped the earth." This reshaping, while creating tremendous progress and prosperity for many people, has also resulted in vast devastation to the planet, its ecosystems, and to nonhumans. Even though the devastation is visible and pervasive, much of the harm inflicted by humans remains outside the realm of and is not addressed by our criminal justice systems (Davies et al. 2014). Such harms tend not to be criminalized and while they may be

Tanya Wyatt

tanya.wyatt@northumbria.ac.uk

1 Northumbria University, Newcastle upon Tyne, UK

2 University of Glasgow, Glasgow, UK 
regulated, such regulation has not led to the overall preservation of the environment or to the protection of non-human life.

For example, it is estimated that the global average atmospheric carbon dioxide in 2017 was 405.0 parts per million-higher than at any point in the last 800,000 years (Lindsey 2018). National Geographic (No date) reports that "[f]orests still cover about 30 percent of the world's land area, but swaths half the size of England are lost each year." And, even though Dirzo and colleagues (2014: 401) admit that the impact of the "Anthropocene defaunation" is uncertain, they claim that an estimated 1500 species have become extinct, including 322 species of terrestrial vertebrates. All of this shows how present regulations are not leading to the conservation of the Earth or the flora and fauna on the planet.

Indeed, weak and inconsistent environmental regulations across the globe have enabled multinational corporations to increase their profits, but without economic benefits to local communities. We will demonstrate this kind of relationship between the economy and the environment by revisiting the closure of Rio Tinto Alcan's Lynemouth aluminum plant in North East England. Our local-global-local perspective illustrates that there are continuing tensions between social and environmental justice. The aluminum smelter has been replaced by a concrete manufacturer that is, arguably, just as polluting and environmentally harmful as the previous manufacturing industry on the same site. Our reflections highlight how equality and justice, as well as human and environmental well-being, are compromised and how corporate actors harm both the economy and the environment.

Global climate change poses a threat to human life and the vitality of the Earth's ecosystems. As reported by the United Nations Intergovernmental Panel on Climate Change (IPCC 2017), human activity, via greenhouse gas emissions, is responsible for global warming; a global response is needed. Our example of the closure of an aluminum smelter highlights the flaws of existing environmental legislation; the Lynemouth plant closure shows how European Union (EU) laws are not enough because polluting companies can move elsewhere only to be replaced by other polluting companies. Our example also highlights that (purported) renewable sources are not always an improvement, particularly when the primary material is not in the same country. The company currently operating the Lynemouth power station is powered using biomass from Canada and the United States (US). Here, a significant portion of the greenhouse emissions produced likely comes from transport to the plant, instead of from it. This case is an example of how companies are redefining the meaning of "green." They are appearing as green by buying green products (biomass), but their whole production process is likely as damaging as it would have been had the power station still been powered by coal. Globally oriented laws, while well intentioned, may have negative impacts on local communities. To address the ethical challenges and trade-offs that accompany global responses, social and environmental justice analyses must embrace the "glocal." We must find ways to mitigate anthropogenic global climate change without resorting to laws that negatively affect some communities more than others (and that may not have much of an impact on the global environment anyway). We begin our discussion of these issues by providing some background information on the socio-economic and environmental context of the Lynemouth plant. Next, we describe the current status of the people, community and environment of the area. We then discuss the corporate discourse of Rio Tinto Alcan, as well as that of the new owners of the site, who portray their actions as socially and environmentally responsible. 


\section{Background of the Lynemouth Plant}

\section{Socio-Economic Context}

Prior to 2007, the Canadian-owned company, Alcan, as it was known then, operated in the Wansbeck District of the English county of Northumberland - the northernmost county in England. ${ }^{1}$ Northumberland is the least densely populated English county with large tracts of national park land and areas of outstanding natural beauty. The unemployment rate is $4.3 \%$, which is only slightly above the national average of $4.2 \%$ (NOMIS 2017). This unemployment rate does not, however, reflect the fact that the southeast part of the county, where Alcan was located, is one of the most deprived areas in England (see Northumberland Knowledge 2015). In 2018, 97.4\% of English postcodes were considered less deprived than NE24 1NT, the Croft electoral ward, where the Port of Blyth is situated (Get the Data 2018). Overall, the North East is a "region of fragments, a region shaped by an industrial past, then fractured by the upheaval of deindustrialisation and, now, a patchwork of places of renewal and decay" (Robinson 2002: 317).

In the 1960s, most of the industries in the North East of England, in general, and in Northumberland, in particular, began to decline. Shipbuilding essentially ceased, docks closed, and the fishing industry shrank dramatically. In the 1980s, the coal mines, located in Lynemouth, also began to close. To be sure, these closures were not peculiar to the North East of England; they were part of the declining coal industry throughout Europe. The impact, however, was severe. Many of these small communities are geographically isolated and relied on one industry to employ the local population. When that industry closed, thousands of people in Lynemouth and the surrounding area were left unemployed (see Spence and Stephenson 2007; Stead 1987; Waddington et al. 1991). Many were also left emotionally, and some physically, scarred by the miner's strike of 1984-85 (Stead 1987).

Due to social and economic degeneration, the British government gave Alcan £28 million to help reduce unemployment in this particular region of the North East of England (see Davies 2014). Not only was there already a workforce in place, but there were also transport links to the Port of Blyth to the east on the North Sea coast so that essential materials for the production of the aluminum and fuel for the power station could arrive at the port and be moved by rail to Lynemouth.

Smelting aluminum is a high-energy manufacturing process. Ironically, the plant at Lynemouth used imported coal in the accompanying power station. Coal is not as efficient as hydroelectric power, for example, and unlike hydroelectricity, it is a major source of carbon emissions and air pollution.

In 2011, Jacynthe Côté, the President and Chief Executive Officer of RTA at the time, announced the closure of the plant:

This decision follows a thorough strategic review which explored every possible option for continuing to operate the smelter and power station. However, it is clear the smelter is no longer a sustainable business because its energy costs are increasing

\footnotetext{
1 In 2007, Alcan was acquired by the Australian-British multinational corporation, Rio Tinto, and became "Rio Tinto Alcan." In 2015, Rio Tinto announced that it would strike the "Alcan" name from its corporate identity (La Presse Canadienne 2015). It is now known as the aluminum division of Rio Tinto. For the sake of simplicity and because much of what we discuss in this article took place prior to 2015, we will use the name "Rio Tinto Alcan" or "RTA" throughout the article.
} 
significantly, due largely to emerging legislation. We are hopeful that the power station can remain in operation under new ownership. [as quoted in Sharp 2011]

Various parts of the plant continued to operate through 2012, however, fulfilling previous orders. At that point in time, the plant directly employed 515 people with an additional 111 people employed at the local coal-fired power station. Another 200 people were contract workers at the plant and hundreds more people in the area were employed in jobs indirectly connected to the plant. We will return to the impact of the Lynemouth plant closure on the former RTA employees later in this article. We now turn to a discussion of the impact of the aluminum smelter and power station on the environment in and around Lynemouth.

\section{Environmental Context}

While the plant was in operation, RTA invested heavily in the plant's environmental performance. In 2009, according to RTA's own Environmental Report, the power station was one of the best in its class in terms of $\mathrm{CO}_{2}$ emissions (RTA 2009). In order to improve its environmental record, the plant began to incorporate biomass into its fuel for the power station, along with coal, and intended to increase the use of biomass. Yet, the $\mathrm{CO}_{2}$ emissions of the power station were still 2.5 million tons (the plant emitted an additional 350,000 tons), which prompted the company to explore funding for carbon capture and sequestration technology for one of the three units at the power station. RTA was interested in reducing emissions by collecting the $\mathrm{CO}_{2}$, bringing it to the coast, and then transporting the captured carbon through an under-sea pipeline to an aquifer offshore, where it would be stored. Addition of the carbon capture and storage technology at the Lynemouth plant seemed likely after a visit in 2009 from then-Prime Minister Gordon Brown, who discussed the retrofit project as a possible investment opportunity by the government.

Carbon capture became a moot point in April 2010, when the European Court of Justice (ECJ) deemed the RTA plant at Lynemouth a large combustion plant. The UK government had been trying to argue that RTA's plant in Lynemouth was not such a plant, but the ECJ decision sealed the fate of the Lynemouth plant because the ruling required the company to comply with the emissions limitations set out in the Kyoto Protocol, which were brought into force under European Directive 2001/80/EC. The plant was given only a few weeks to comply or the government would incur fines for not doing so. The cost for compliance between 2011 and 2015 would have been $£ 105$ million, which would have meant that RTA would not have been able to meet its criterion of a $40 \%$ rate of return (Davies 2014). Rather than attempt to make the plant compliant with the government's need to adhere to the newly enforced higher emissions standards, which would have reduced the profitability of the company, RTA closed the plant.

Not only is aluminum smelting harmful to the surrounding environment, but it is also known to be problematic for people employed in the industry. There is mounting evidence of the adverse human health consequences and public health effects arising from both generalized and occupational exposure to pollutants (Davies 2017). Kudaeva and colleagues (2016) claim the aluminum production industry is one of the most dangerous for the health of the workers. Costello and colleagues (2014) found elevated rates of heart disease among aluminum workers, while Noth and her co-authors (2014) similarly report on heightened exposure to small particle matter pollution that results from aluminum smelting. Aluminum production plant workers are at risk of exposure to the metals and chemicals (Buranatrevedh 2010: 136) and the aluminum production process increases the exposure to dust and gasses, which are also potentially harmful to the workers and the local environment (Kongerud and 
Søyseth 2014). This exposure can lead to respiratory diseases in workers, such as potroom asthma, or cancer (see Kongerud and Søyseth 2014; Romundstad et al. 2000). Romundstad and his collaborators (2000) found in their study that an elevated risk of developing bladder and kidney cancer exists for those exposed over long periods of time to the polycyclic aromatic hydrocarbons generated by the combustion of both fossil fuels and biomass. That is not to say that the workers at Lynemouth are or were aware of these health risks or that they are or have been experiencing them. Rather, our point is that, in general, this type of industry is harmful to the people who work in it and to the wider environment.

As noted above, historically, the people in the area surrounding the plant have experienced high levels of deprivation. The marginalization and inequity at the core of deprivation were not stalled or reversed by replacing one environmentally harmful industry - coal mining — with a modern manufacturing process (aluminum smelting). In fact, situating environmentally harmful industries in deprived areas has been found to be disproportionate in the UK (Walker et al. 2005) and elsewhere (Agyeman and Evans 2004). The next section explores further the socio-economic and environmental context of the local area and brings the story of the site to the present by illustrating how the aluminum smelter has been replaced by a concrete manufacturer that is arguably just as environmentally damaging. We also draw connections to global aluminum markets.

\section{Lynemouth Today}

\section{Current Socio-Economic Context}

After the announcement of the likely closure of Rio Tinto Alcan in 2011, more than 500 people faced unemployment in the southeast of Northumberland (BBC 2011). The Northumberland County Council Councillor, Jeff Reid, highlighted the impact that the closure would have on families (BBC 2011) because RTA was the largest private sector employer in the southeast of Northumberland (Rio Tinto 2016). Following a 90-day consultation with employee and union representatives, on 6 March 2012, it was confirmed that RTA would close the Lynemouth aluminum smelter and that 323 people would lose their jobs (BBC 2012) — a huge impact on the community. As Tom Brennan, regional secretary of the General, Municipal, Boilermakers and Allied Trade Union (GMB) said:

This announcement is a body blow for the economy of south Northumberland as this was the last major manufacturing plant in the area [...]It now leaves the public sector as the only major employer in the area. It will be very hard for the workers and their families to get new work (quoted in BBC, 2012:1).

Even though the closure of the plant left many people unemployed, RTA assured them that some measures would take place in order to minimize the impact. For example, Dodds (2014) reported: "Rio Tinto organised CV workshops and interview coaching for its workers as well as donating a $£ 630,000$ 'legacy fund' to local projects.” Later, in mid-2012, after the announcement of the closure of the Lynemouth plant, RTA's Regional Economic Development team focused on developing a lasting positive legacy for the site by attracting new investment and supporting local communities (Rio Tinto 2016). Then-President and CEO Jacynthe Côté, mentioned above, stated: "We will now focus on safely decommissioning the plant, working with our employees to mitigate the impact of redundancy 
on them and their families and partnering with all interested stakeholders on the future regional economic development of the Lynemouth site" (quoted in BBC 2012).

RTA's Regional Economic Development team worked along with local politicians, the Northumberland County Council, the North East Local Enterprise Partnership, and Arch Northumberland to address the pending unemployment. Furthermore, these organizations also collaborated with non-governmental organizations (NGOs), including non-profit/voluntary sector groups, academia, and the UK government (UK Trade and Investment and the Department of Business, Innovation and Skills) to try to make sure that the employees received all the assistance needed to improve or expand their skill sets and, therefore, to help them to find new job opportunities (Rio Tinto 2016). RTA kept supporting the community after the closure of the plant by giving donations to initiatives aimed to create a stronger and self-sustaining community (Rio Tinto 2016).

Not everyone who lost his or her job experienced unemployment or was impacted by unemployment in the same way. As reported by the Northumberland County Council in 2012, the process operatives were those most affected by the plant closure because of their lack of transferable skills (Braidford et al. 2012). Trades workers, management, and other professionals had more opportunities because other industries or businesses were interested in their experience and abilities.

Braidford and colleagues (2012) reported how the workers most likely to face long-term unemployment were lower-skilled administrative, process and technical staff. When these individuals did find employment, it was more often than not part-time or with lower pay:

Those who take longer to find a job would be more likely to switch sectors and/or occupations, have lower wages, more unstable employment terms and a lower level of personal (and family) wellbeing. As such, training in other occupational areas may be necessary, but should not necessarily be recommended in the first instance.

(Braidford et al. 2012: 5)

Because lower-skilled workers are more likely to take longer to find a job, Braidford and colleagues (2012) recommended that Northumberland County Council pay special attention to these workers, advising the council to train the former Lynemouth workers as to how to claim benefits, manage finances and pursue self-employment. They also emphasized working with other stakeholders, such as colleges and the Jobcentre Plus. ${ }^{2}$ Finally, Braidford and colleagues (2012: 5) suggested providing advice and support to the workers' families and wider communities because unemployment can impact them as well: "It would be helpful to remain in contact with former workers for as long as possible after the closure, as outcomes are not immediate and support needs may change over time."

Workers with limited means of transportation are often those most impacted when an industry or plant closes. This was no different for the Lynemouth workers; those workers who could not travel outside of the local area because of a lack of transportation or a lack of funds to support commuting experienced longer periods of unemployment. Lack of mobility also tends to correlate with lack of skills, meaning that those with less education and training were also those most circumscribed geographically. Nevertheless, RTA reported that the majority of its former workforce had been redeployed or had found a new job. The company also maintained that " $90 \%$ of the workforce had since found new jobs, become self-employed, retired or gone into full-time education" (Dodds 2014).

\footnotetext{
2 Jobcentre Plus, which is part of the Department for Work and Pensions, delivers working-age support services in the United Kingdom.
} 
Today, "[t]he former aluminium smelter site is now home to a range of industrial activities, operating autonomously, but under the umbrella of the site's new landlord, Harworth Estates Investments Ltd [hereinafter, Harworth]" (Rio Tinto 2016: 2), who bought the site in 2015. Harworth has created an employment park to attract different businesses and create more job opportunities (ITV 2017). There are approximately 100 people now working in the former RTA plant area and it is possible for up to 500 more jobs to be created at the site (ITV 2017). According to Iain Thomson of Harworth, the conditions of the site are optimal to create the employment park because the rail connections are in place and the site is close to the Port of Blyth-the same reasons that the site was suitable for RTA (see ITV 2017). In addition, Harworth (2018) has emphasized that the redevelopment of the Lynemouth Park is a really important program for Northumberland and its community.

\section{Current Environmental Context}

When RTA announced the closure of the plant, one of its major stated objectives was proper decommissioning. Decommissioning started in 2012 and ended approximately four years later with the ground clearance of where the smelter plant's chimneys once stood (The Construction Index 2018). (The chimneys been demolished through controlled explosions (BBC 2016).) As Insider Media (2015) reported,

The decommissioning process has been led by Rio Tinto's own team and has involved the removal of plant and machinery, the demolition of some buildings and cleaning the site to enable the return of its operating permit to the industry regulator, the Environment Agency.

Parts of the decommissioning process were highly complex; thus, some were planned to take up to 40 weeks in order to ensure the safety of everyone involved (Rio Tinto 2016). Indeed, as the company itself reported, "[o]nly one activity was carried out in any one building at a time" (Rio Tinto 2016: 2).

Decommissioning the site was planned in stages and the first stage took place at the carbon plant. RTA employees, alongside contracted workers, started to demolish, clean, and prepare the carbon plant, so that the building could be considered for new opportunities (Rio Tinto 2016). Even though RTA demolished most of the Lynemouth plant, some of the structures were left intact for buyers who had agreed to clean them themselves. This was the case for the potrooms ("where aluminium was produced in structures called pots by a process of electrolytic reduction" (Rio Tinto 2016: 2)), which remained intact for the new owners, who agreed to clean and repair as needed.

Harworth (2018) reports that there are two current occupiers of the site: LYNX Precast and H-MIX Limited. LYNX Precast manufactures and installs precast concrete flooring products, while H-MIX manufacturers ready-mixed concrete (H-MIX, No date). From our research, it appears that neither company offers any kind of data on their respective websites or reports on environmental statistics, such as the sustainability of the raw materials, their source, or the $\mathrm{CO}_{2}$ emissions during the manufacturing process. (The LYNX Precast website does, however, contain a copy of the company's Environmental Management SystemISO 14001 (LYNX Precast, No Date).)

The International Standards Organisation (ISO) 14001 has become the international benchmark for companies to assess their environmental impact (Rondinelli and Vastag 2000). The voluntary guidelines provide a means to develop environmental policy, set objectives and targets, and implement a program to monitor and evaluate progress, among 
other environmentally-focused goals. The LYNX Precast document shows that the company complies with the requirements of ISO 14001 during the design, manufacture, delivery, and installation of their products. As claimed by Rondinelli and Vastag (2000: 499), the ISO 14001 serves to improve the environmental management of a firm, but "some firms may, indeed, simply use ISO 14001 as a 'label' for image-building."

After water, concrete is the most used substance on the planet (WBCSD 2002). The main ingredient of concrete is cement, which is made up of sand, aggregates, and water. Creating cement and concrete is energy intensive, involving chemical processes under high heat. Thus, cement and concrete, through these chemical processes and their use of fuel, typically fossil fuels like oil and coal, produce greenhouse gasses. The industry contributes $5 \%$ to the world's $\mathrm{CO}_{2}$ emissions - a figure that is expected to double by 2050 (WBCSD 2002)-making cement the third largest human-made source of $\mathrm{CO}_{2}$ (GreenSpec 2018). Depending on the fuel burned and amount of transportation involved, cement production and aluminum production emit the same amount of $\mathrm{CO}_{2}$ (780 $\mathrm{kg} \mathrm{CO}_{2}$ per 1 ton of product) (Greener Industry, No Date; GreenSpec 2018). Concrete production also emits sulfur compounds and nitrogen oxides. Sulfur dioxide and nitrogen oxide react with water molecules in the atmosphere to produce acid rain, which harms the lungs of human and non-human animals and damages forests and buildings (WBCSD 2002). Nitrogen oxide contributes to local air pollution through particulate matter accumulating in low-level clouds. Such smog can cause respiratory ailments (WBCSD 2002).

In addition to the presence of LYNX Precast and H-MIX on the site, the Crown Estate owns agricultural land at the former plant, containing farm buildings, homes, and wind turbines (Rio Tinto 2016). Other parcels of land have been donated to community groups, including Ellington Juniors Football Club, Ellington and Linton Parish Council, and Lynemouth Cemetery (Morpeth Herald 2014). The Crown Estate and Harworth, the owners of the site, claim a strong commitment to the responsible and sustainable regeneration of the land (Rio Tinto 2016). These entities' green intentions are important to note, as is the fact that, according to Rio Tinto (2016: 2), "[m]ore than 90 percent of the materials generated through decommissioning and demolition on the existing site has been reused or recycled."

One of the effects of the Lynemouth closure was the increase of aluminum imports to Britain (Merlin-Jones 2012). Britain has always relied on imports, mostly from the rest of the EU, and the closure of the plant in Lynemouth did little to change this (although, as Merlin-Jones (2012) notes, imports from China and Russia increased due to their low energy costs). The closure of the aluminum smelters in the UK and the subsequent reliance on imported aluminum has, as a result, "boost[ed] the demand for recycled aluminium" (Merlin-Jones 2012: 11). With 39 plants in operation, the shift to recycled aluminum can be viewed in positive terms because recycled aluminum uses only $5 \%$ of the energy required to produce new aluminum (Merlin-Jones 2012).

As noted above, high levels of deprivation remain a problem for the Lynemouth area and the southeast region of Northumberland. While it seems that most of the displaced workers from the smelter have found employment, their individual experiences and current circumstances are unknown. Whereas it may have appeared to be an environmental victory that the plant closed because of improved emissions standards, the reality is more complex. The aluminum smelter has been replaced by a concrete manufacturer that is, arguably, just as polluting and environmentally harmful. It may be the case that the concrete manufacturer emits less pollution, but manufacturing industries, in general, remain significant polluters, which impact the surrounding (and global) environment and the workers employed in these industries. As one of us has argued, while the closure of the RTA plant at Lynemouth can be considered a success in green terms on a national level (Davies 2014, 2017), the aluminum that used to be made in Lynemouth is still being produced; it is just that now, 
this production is taking place in other parts of the world in locations with less restrictive $\mathrm{CO}_{2}$ standards and targets. Thus, at a global level, the direct impacts of environmental harm have been displaced and overall harm has not been reduced. If one were to rely only the information from the manufacturing company or corporation, one would not know that core social and environmental injustices persist in the local area.

\section{Corporate Discourse}

It is important to emphasize that most of the information regarding the social and environmental improvements to the area is originating from and being distributed by the previous corporate owner and current manufacturing companies. These multinational corporate entities have a clear stake in depicting themselves and being portrayed as caring for the people and environment of Lynemouth. Thus, it is possible that the picture given by the corporations is not exactly the reality in terms of the community's and former workers' well-being or the health of the environment. This seems particularly possible concerning the environment given that a large combustion biomass power station and a concrete factory have replaced a large combustion coal power station and an aluminum smelter. We explore the corporate narrative around the changes to Lynemouth in the following sections.

\section{Whitewashing?}

As described above, RTA and the new companies that have moved into the Lynemouth site have all made claims that they have helped the former workers to find new jobs or to be retrained, or have contributed funds to community projects. Indeed, these businesses appear to have made efforts to mitigate the effects of the plant's closure. There seems, however, no way to measure the specific impact that their efforts have had on the individual workers. Is the corporate narrative of helping former employees in the area a form of corporate whitewashing? In this context, whitewashing, like greenwashing, discussed below, is a form of communication put forth by a company that presents the company's corporate behavior in the best possible light in terms of environmental and social justice. For instance, "ethical trading" schemes and corporate codes of conduct, which promise to have positive impacts on rural livelihoods, have been called "whitewashing" because in reality, they have little to no positive impact on the people the corporations are claiming they have helped (du Toit 2001). Instead, the corporation appears to be concerned with social justice, when in fact, its actions are not providing substantial benefit. In the case of Lynemouth, what is perhaps most telling with respect to the effectiveness of corporate efforts is that the area remains one of the most deprived in the UK. Whereas some people may have, indeed, found gainful employment, these benefits are not universal and have not brought about a reduction in the high levels of deprivation in the area. Meanwhile, the corporations publicize the efforts they have made to help people, while they appear to have experienced no adverse effects from closing the plant as their production levels and profits remain strong.

\section{Greenwashing?}

As a company, RTA has demonstrated its commitment to addressing climate change through a series of initiatives presented on its website. It declares that it recognizes that 
the climate is changing due to human influences, and it outlines its efforts to try to minimize its impact on the environment. RTA acknowledges that it is an energy-intensive business that emits greenhouse gasses from its plants that produce metals, from its mining minerals, and during the transportation of fuel to its power stations and during the transportation of its finished materials to its buyers. To demonstrate its commitment to reducing its contributions to climate change, it has stated that it will be "cut[ting] our GHG emissions intensity by 27 percent between 2008 and 2017" (Rio Tinto 2018: 1). In addition, Rio Tinto (2018: 1) highlights in its commitment statement that $75 \%$ of its energy comes from hydro, nuclear, and renewable power sources: "Around 80 percent of the Aluminium group's power needs comes from carbon-free sources, with 57 percent generated by our own hydropower assets."

These assertions notwithstanding, in 2013, RTA sold the Lynemouth power station to German-based electric utilities company, RWE. The new owners of the power station operated using the same workforce, intending to switch fuel from coal to biomass (Gosden 2016; RWE 2012). Before making the conversion to biomass, RWE sold the power plant to EPH (Energetický a průmyslový holding), a Czech-based company, which plans to convert the plant so that it can be fuelled by wood pellets (Gosden 2016). The plant is expecting to produce up to 390 megawatts of low carbon electricity (Lynemouth Power Ltd. 2018a). Lynemouth Power, Ltd. (2018b: 1) specifies on its website that it would use "sustainably-sourced, renewable wood pellets to fuel the power station" and that these pellets would come from Canada and the US. The company also said that the biomass pellets burned in the power station would ensure both environmental and social sustainability.

It is important to highlight that biomass is not always considered renewable or sustainable because it is "a source of energy that is generated by combustion and results in the direct emission of fine particulates, biomass is like coal, oil, and natural gas" (Ahlers 2016: 49). Furthermore, how is biomass coming from thousands of miles away, and thus responsible for thousands of tons of $\mathrm{CO}_{2}$ emissions from the transportation of the biomass, environmentally or socially sustainable? It seems that RTA, RWE, and EPH have engaged in greenwashing - where, as noted above, companies paint themselves as environmentally friendly (or "green") by highlighting some behaviors over others (Lynch and Stretesky 2003). This is problematic because it gives the false impression that environmental harm is being reduced and that efforts are being made to stop global warming and reduce the adverse impacts of climate change. In fact, the environmental harm is being displaced and, on a global level, carbon emissions are starting to increase (Global Carbon Project 2018); thus, it seems that few significant efforts are being undertaken by these corporations to earnestly reverse global warming.

\section{Social Justice Versus Environmental Justice}

The world needs to reduce $\mathrm{CO}_{2}$ emissions in order to prevent a global catastrophe, but has failed to do so (Xu et al. 2018). Even before this realization, the threat of impending climate change has brought the development of a range of environmental laws in the EU and around the world. We are just beginning to explore the extended social harms and victimization - the challenges and trade-offs - that we will encounter.

Alongside other scholars, many of whom are contributors to this special issue, we are building on key developments within the critical criminological tradition, most notably, 
Ruggiero and South's (2013) concerns about crimes of the economy as they affect the environment. Our own illustrative case study has, using an interdisciplinary approach, revisited the closure of RTA aluminum plant in Lynemouth, Northumberland, in the North East of England. Ruggiero and South (2013: 365) explain that "[p]rinciples of equity, social justice and collective wellbeing are overshadowed by calculations of output and development." We, too, have attempted to illustrate how "principles of equity, social justice and collective wellbeing" are compromised and how corporate actors harm both the economy and the environment.

In our example, the local community could be understood as victimized because of the loss of jobs in a deprived area. Arguably, however, the community suffered prior to the Lynemouth plant closure. As Bisschop and Vande Walle (2013: 40) claim in relation to the environmental harm of waste, "victims of e-waste dumping often don't know they are harmed, or they accept the harm because they need the e-waste business to survive." Similarly, it is likely that the aluminum workers were not and may still not be aware of the harms caused by the industry in which they worked. Or, the workers may have realized the harm, but accepted it because it was their only means to a secure income. The community of Lynemouth — and others like it—faced two types of harm: social injustice in the short and probably long-term, due to the loss of jobs and on-going deprivation, and environmental injustice in the exposure to high levels of air pollution. Green criminologists have shown that environmental harms disproportionately impact marginalized groups (e.g., the poor, racial and ethnic minorities), while the powerful are largely protected from these adverse effects (Stretesky 2003; Stretesky and Lynch 2002; White 2007, 2011). In our example, the UK government incentivized a known-polluting manufacturing plant, the Lynemouth aluminum smelter, to locate in a deprived area. The situation raises moral and ethical challenges to try to find a balance between social and environmental justice.

Further ethical challenges arise from the "glocal." The southeast of Northumberland is a particularly acute example of areas across the UK that are suffering disproportionally the effects of deindustrialization and the impact of the contraction of manufacturing industries. In 2013, the area experienced another great blow due to the loss of the principal employer within the deprived area. The closure of the plant left employees and others indirectly supported by the site in a financially precarious position. Although the local economy was affected heavily by EU environmental laws, the company, Rio Tinto, remains one of the largest, most profitable mineral and mining multi-nationals in the world. It simply moved its operations somewhere else.

This leads us to a second "glocal" issue: EU environmental laws were created to reduce $\mathrm{CO}_{2}$ levels - a global issue and concern. Yet, corporations unwilling to comply with planetsaving environmental legislation are able to move to countries with weaker environmental legislation, thus negating the global improvements at the heart of such legislation and likely further harming marginalized and/or deprived communities in their new location. In addition, if some parts of the world limit $\mathrm{CO}_{2}$ emissions (IPCC 2017), while others such as the China, Russia and the US do not (see Independent 2018), limiting $\mathrm{CO}_{2}$ at all may prove pointless in the global context of climate change. 


\section{Conclusion}

In this article, we have explored the relationship between the economy and the environment, revisiting the closure of the RTA aluminum plant in Lynemouth, Northumberland, in the North East of England. In so doing, we have observed that many of the original concerns of the tensions between social and environmental justice and the local and the global remain. Our reflections highlight how equality and justice, as well as human and environmental well-being, are compromised and how corporate actors harm both the (local) economy and the (local and global) environment.

Global climate change should be one of, if not, the main concern of everyone as it threatens the survival of people and the ecosystems of our planet. The IPCC (2017) continues to highlight that human activity, via greenhouse gas emissions, is responsible for global warming and that it is critical that we respond as a global community. Our example of the closure of an aluminum smelter exposes the challenges and the flaws of existing environmental legislation that has global intentions, but local negative consequences; the Lynemouth plant closure shows how EU laws are not enough because polluting companies can move elsewhere only to be replaced by other polluting companies. These polluting companies, though, portray themselves as "green" by focusing on their use of (purportedly) renewable energy sources (biomass that has been transported thousands of miles) and their recycling of old materials (the components of the aluminum smelter were reused in other smelters or recycled). Fossil fuel and biomass burning and the production processes reliant on them are not green energy. These companies also portray themselves as socially responsible by providing résumé writing workshops and legacy funds in areas that the companies have left in favor of places with less restrictive environmental regulations. International laws to combat climate change, while well intentioned, may have negative socioeconomic impacts on local communities. To address the ethical challenges and trade-offs that accompany global responses, social and environmental justice analyses must embrace the "glocal." We must find ways to mitigate anthropogenic global climate change-and protect communities as much as possible. Holding corporations accountable for lessening their global footprint and for not affecting marginalized communities disproportionately in their hunt for profit is key to achieving social and environmental justice. Although this is challenging, this should not discourage us from exploring global responses in order to prevent the devastating consequences of failing to respond.

OpenAccess This article is distributed under the terms of the Creative Commons Attribution 4.0 International License (http://creativecommons.org/licenses/by/4.0/), which permits unrestricted use, distribution, and reproduction in any medium, provided you give appropriate credit to the original author(s) and the source, provide a link to the Creative Commons license, and indicate if changes were made.

\section{References}

Agyeman, J., \& Evans, B. (2004). 'Just sustainability': The emerging discourse of environmental justice in Britain? The Geographical Journal, 170(2), 155-164.

Ahlers, C. D. (2016). Wood burning, biomass, air pollution, and climate change. Environmental Law, 46(1), 49-104.

BBC. (2011). Alcan Northumberland site closure hits 500 jobs. BBC News. 16 November. Available at: http://www.bbc.co.uk/news/mobile/uk-england-tyne-15759425. Accessed 3 Oct 2018.

BBC. (2012). Hundreds of jobs lost as Alcan Lynemouth smelter closes. BBC News. 6 March. Available at: https://www.bbc.co.uk/news/uk-england-tyne-17270150. Accessed 1 Oct 2018. 
BBC. (2016). Alcan Lynemouth smelter chimneys demolished. BBC News. 13 June. Available at: https:// www.bbc.co.uk/news/uk-england-tyne-36515700. Accessed 9 Oct 2018.

Bisschop, L., \& Vande Walle, G. (2013). Environmental victimisation and conflict resolution: A case study of e-waste. In R. Walters, D. Westerhuis, \& T. Wyatt (Eds.), Emerging issues in green criminology: Exploring power, justice, and harm (pp. 34-56). London: Palgrave Macmillan.

Braidford, P., Hunt, A., \& Stone, I. (2012) Rio Tinto Alcan Lynemouth closure: Evidence of likely economic impact. May. Available at: https://www.northumberland.gov.uk/NorthumberlandCountyCounc il/media/Northumberland-Knowledge/Document\%20library/Alcan-Closure-Economic-Impacts-Repor t_FINAL_30-05-12.pdf. Accessed 3 October 2018.

Buranatrevedh, S. (2010). Health risk assessment of workers exposed to metals from an aluminium production plant. Journal of the Medical Association of Thailand, 93(7), S136.

Costello, S., Brown, D. M., Noth, E. M., et al. (2014). Incident ischemic heart disease and recent occupational exposure to particulate matter in an aluminium cohort. Journal of Exposure Science \& Environmental Epidemiology, 24(1), 82-88.

Crutzen, P. J., \& Stoermer, E. F. (2000) The "Anthropocene". IGBP (International Geosphere-Biosphere Programme) Newsletter, 40(May), 17-18. Available at: http://www.igbp.net/download/18.316f183213 23470177580001401/1376383088452/NL41.pdf. Accessed 17 Oct 2018.

Davies, P. A. (2014). Green crime and victimisation: Tensions between social and environmental justice. Theoretical Criminology, 18(3), 300-316.

Davies, P. A. (2017). Green crime, victimization and justice: A rejoinder. Critical Sociology, 43(3), 465-471.

Davies, P., Francis, P., \& Wyatt, T. (2014). Introduction. In P. Davies, P. Francis, \& T. Wyatt (Eds.), Invisible crimes and social harms (pp. 1-25). Basingstoke, Hampshire: Palgrave Macmillan.

Dirzo, R., Young, H., Galetti, M., Ceballos, G., Isaac, N., \& Collen, B. (2014). Defaunation in the anthropocene. Science, 345(6195), 401-406.

Dodds, L. (2014). Alcan owners apply to demolish chimneys at Lynemouth aluminium smelter. The Journal. 11 April. Available at: http://www.thejournal.co.uk/news/north-east-news/alcan-owners-apply -demolish-chimneys-6949580.

Du Toit, A. (2001). Ethical trading: A force for improvement or corporate whitewash?. Natural Resource perspectives. Available at: http://dlc.dlib.indiana.edu/dlc/bitstream/handle/10535/3945/71-ethical-tradi ng.pdf?sequence=1\&isAllowed=y. Accessed 15 Dec 2018.

Get the Data. (2018). Available at: https://www.getthedata.com/postcode. Accessed 26 October 2018.

Global Carbon Project. (2018). Global carbon budget. Available at: http://www.globalcarbonproject.org/ carbonbudget/. Accessed 15 December 2018.

Gosden, E. (2016). RWE sells Lynemouth power plant to EPH ahead of biomass conversion. The Telegraph 7 Jan. Available at: https://www.telegraph.co.uk/news/earth/energy/coal/12088002/RWE-sells-Lynem outh-power-plant-to-EPH-ahead-of-biomass-conversion.html. Accessed 10 November 2018.

Greener Industry. (No Date) Aluminium. Available at: http://www.greener-industry.org.uk/pages/alumi nium/aluminium_3issues.htm. Accessed 30 October 2018.

GreenSpec. (2018). The environmental impacts of concrete. Available at: http://www.greenspec.co.uk/build ing-design/environmental-impacts-of-concrete/. Accessed 30 October 2018.

Harworth. (2018). Lynefield park, Lynemouth: Centre of Harworth's Nortumberland regeneration plans. Available at: https://harworthgroup.com/projects/lynefield-park/. Accessed 12 October 2018.

H-MIX. (No date) Home. Available at: http://www.hmix.co.uk/. Accessed 10 November 2018.

Independent. (2018). How can we seriously tackle climate change when one of the biggest barriers to reducing emissions is sitting in the White House? Editorials. 8 October. Available at: https://www.indep endent.co.uk/voices/editorials/un-ipcc-donald-trump-climate-change-co2-emissions-paris-agreementchina-a8574231.html. Accessed 18 October 2018).

Insider Media. (2015). Former Rio Tinto smelter site acquired. Available at: https://www.insidermedia.com/ insider/northeast/137697. 16 April. Accessed 10 October 2018.

Intergovernmental Panel on Climate Change. (IPCC). (2017) Global warming of $1.5{ }^{\circ} \mathrm{C}$. Available at: http:// www.ipcc.ch/report/sr15/. Accessed 14 October 2018.

ITV. (2017). 500 jobs could be created at former Alcan site in Northumberland. Available at: http://www.itv. com/news/tyne-tees/2017-09-29/500-jobs-could-be-created-at-former-alcan-site-in-northumberland/. 29 September. Accessed 3 October 2018.

Kongerud, J., \& Søyseth, V. (2014). Respiratory disorders in aluminum smelter workers. Journal of Occupational and Environmental Medicine, 56(5), 60-70.

Kudaeva, I. V., Dyakovich, O. A., Masnavieva, L. B., Popkova, O. V., \& Abramatets, E. A. (2016). Features of the lipid exchange in workers employed in aluminium productions. Gigiena i sanitaria, 95(9), 857. 
La Presse Canadienne. (2015). Abandon du nom Alcan: le gouvernement Couilllard hauuse les épaules. Les Affaires. 12 May. Available at: https://www.lesaffaires.com/secteurs-d-activite/ressources-naturelles/ abandon-du-nom-alcan-le-gouvernement-couillard-hausse-les-epaules/578706.

Lindsey, R. (2018). Climate change: Atmospheric carbon dioxide. National Oceanic and Atmospheric Association. Available at: https://www.climate.gov/news-features/understanding-climate/climate-chang e-atmospheric-carbon-dioxide. Accessed 15 December 2018.

Lynch, M. J., \& Stretesky, P. B. (2003). The meaning of green: contrasting criminological perspectives. Theoretical Criminology, 7(2), 217-238.

Lynemouth Power Ltd. (2018a). About us. Available at: https://www.lynemouthpower.com/about-us/. Accessed 12 October 2018.

Lynemouth Power Ltd. (2018b). Sustainability. Available at: https://www.lynemouthpower.com/sustainabi lity/. Accessed 14 October 2018.

Lynx Precast. (No Date) About us. Available at: https://www.lynxprecast.co.uk/about-us/. Accessed 27 October 2018.

Merlin-Jones, D. (2012). The closure of the Lynemouth aluminium smelter: an analysis. Civitas (April). Available at: https://www.civitas.org.uk/content/files/aluminium2012.pdf. Accessed 5 October 2018.

Morpeth Herald. (2014). Crown estate buys Rio Tinto's Lynemouth farmland. Morpeth Herald. 24 February. Available at: https://www.morpethherald.co.uk/news/business/crown-estate-buys-rio-tinto-s-lynem outh-farmland-1-6457982. Accessed 26 October 2018.

National Geographic. (No Date). Deforestation. Available at: https://www.nationalgeographic.com/envir onment/global-warming/deforestation/. Accessed 27 October 2018.

NOMIS. (2017). Labour Market Profile - Northumberland. Available at: https://www.nomisweb.co.uk/ reports/lmp/la/1946157061/report.aspx?town=northumberland. Accessed 23 October 2018.

Northumberland Knowledge. (2015). A Northumberland analysis of the English indices of deprivation 2015. October. Available at: https://www.northumberland.gov.uk/NorthumberlandCountyCouncil/media/ Northumberland-Knowledge/NK\%20place/Indices\%20of\%20deprivation/IMD-2015-Summary-IDACI .pdf. Accessed 26 October 2018.

Noth, E. M., Dixon-Ernst, C., Liu, S., et al. (2014). Development of a job-exposure matrix for exposure to total and fine particulate matter in the aluminium industry. Journal of Exposure Science \& Environmental Epidemiology, 24(1), 89-99.

Rio Tinto. (2016) Lynemouth aluminium smelter: Northumberland, England. Available at: http://www.rioti nto.com/documents/RT_Lynemouth_Aluminium_Smelter_England.pdf. Accessed online: 5 October 2018.

Rio Tinto. (2018). Energy and climate change. Available at: http://www.riotinto.com/ourcommitment/energ y-and-climate-change-24291.aspx. Accessed 14 October 2018.

Rio Tinto Alcan (RTA). (2009). Environmental report. Lynemouth, England.

Robinson, F. (2002). The north east: A journey through time. City, 6(3), 317-334.

Romundstad, P., Andersen, A., \& Haldorsen, T. (2000). Cancer incidence among workers in six Norwegian aluminium plants. Scandinavian Journal of Work, Environment \& Health, 26(6), 461-469.

Rondinelli, D., \& Vastag, G. (2000). Panacea, common sense, or just a label? The value of ISO 14001 environmental management systems. European Management Journal, 18(5), 499-510.

Ruggiero, V., \& South, N. (2013). Green criminology and crimes of the economy: Theory, research and praxis. Critical Criminology: An International Journal, 21(3), 359-373.

RWE. (2012). Lynemouth Power Station acquisition. 19 December. Available at: https://www.rwe.com/ web/cms/mediablob/en/2527232/data/1360742/1/rwe-supply-trading/press/press-archive/blob.pdf. Accessed 12 October 2018.

Sharp, R. (2011). Alcan confirm the loss of 515 jobs at plant. Blyth News. 14 November. Available at: https ://www.blythtown.net/blyth-news/alcan-confirm-the-loss-of-515-jobs-at-plant. Accessed 12 March 2019.

Shearing, C. (2015). Criminology and the anthropocene. Criminology \& Criminal Justice, 15(3), $255-269$.

Spence, J., \& Stephenson, C. (2007). The politics of the doorstep: Female survival strategies and the legacy of the miners' strike 1984-85. Community, Work and Family, 10(3), 309-327.

Stead, J. (1987). Never the same again: Women and the miners' strike. London: The Women's Press.

Stretesky, P. (2003). Environmental inequity and the distribution of air lead levels across U.S. countries: Implications for the production of racial inequality. Sociological Spectrum, 23(1), 91-118.

Stretesky, P., \& Lynch, M. (2002). Environmental hazards and school segregation in Hillsborough County Florida, 1987-1999. Sociological Quarterly, 43(4), 553-573.

The Construction Index. (2018). Alcan site renewal moves to next stage. 13 March. Available at: https:// www.theconstructionindex.co.uk/news/view/alcan-site-renewal-moves-to-next-stage. Accessed 26 October 2018. 
Waddington, D., Wykes, M., Critcher, C., \& Hebron, S. (1991). Split at the seams? Community, continuity and change after the 1984-5 coal dispute. Milton Keynes: Open University Press.

Walker, G., Mitchell, G., Fairburn, J., \& Smith, G. (2005). Industrial pollution and social deprivation: Evidence and complexity in evaluating and responding to environmental inequality. The International Journal of Justice and Sustainability, 10(4), 361-377.

WBCSD (World Business Council for Sustainable Development). (2002). The cement sustainability initiative: Our agenda for action. July. Available at: https://web.archive.org/web/20070714085318/http:// www.wbcsd.org/DocRoot/1IBetslPgkEie83rTa0J/cement-action-plan.pdf. Accessed 30 October 2018.

White, R. (2007). Green criminology and the pursuit of social and ecological justice. In P. Beirne \& N. South (Eds.), Issues in green criminology: Confronting harms against environments, humanity and other animals (pp. 32-54). Cullompton, Devon: Willan.

White, R. (2011). Transnational environmental crime: Toward an eco-global criminology. Abingdon, Oxon: Routledge.

Xu, Y., Ramanathan, V., \& Victor, D. (2018). Global warming will happen faster than we think. Nature. Available at: https://www.nature.com/articles/d41586-018-07586-5. Accessed 15 December 2018.

Publisher's Note Springer Nature remains neutral with regard to jurisdictional claims in published maps and institutional affiliations. 